\title{
Fingerprint analysis of Bombyx mori local variety resources based on SSR markers
}

\author{
Heying Qian ${ }^{\mathrm{a}, \mathrm{b}}$, Gang Li ${ }^{\mathrm{a}, \mathrm{b}}$, Guodong Zhao ${ }^{\mathrm{a}, \mathrm{b}}$, Mingzhu Liu ${ }^{\mathrm{a}, \mathrm{b}}$, Pingjiang Sun ${ }^{\mathrm{a}, \mathrm{b}}$, Anying Xu ${ }^{\mathrm{a}, \mathrm{b}, *}$ \\ a Jiangsu University of Science and Technology, Zhenjiang, Jiangsu 212003, China \\ b The Sericultural Research Institute, Chinese Academy of Agricultural Sciences, Zhenjiang, \\ Jiangsu 212018, China
}

*Corresponding author, e-mail: srixay@126.com

Received 28 Jan 2019

Accepted 28 Aug 2019

\begin{abstract}
Simple Sequence Repeats (SSR) markers were used to research the fingerprints of 96 silkworm local variety resources, including 83 Chinese univoltine varieties, 11 Chinese bivoltine varieties and 2 Japanese bivoltine varieties. These SSR markers showed rich polymorphism, with the number of alleles reaching 3-35, averaged 12.78, suggesting that there was rich SSR polymorphism among various local varieties and its polymorphism information content ranged from 0.162-0.958, averaged 0.690. The genetic distance between the various varieties was calculated from their fingerprints. By using UPGMA method, unique patterns of clustering among local species of silkworm were revealed. These included the patterns of 5 groups comprising of 54 varieties, while the other 42 species clustered in twos or threes, and as single nodes. In addition, the clustering among varieties did not indicate any obvious groups based on voltinism or moltinism, which seemed to support the theory of multiple origin of silkworm. The results prove that SSR markers can provide a fingerprint analysis of silkworm varietal resources and can be used for their classification and identification.
\end{abstract}

KEYWORDS: Bombyx mroi, simple sequence repeats, local variety resources, fingerprint

\section{INTRODUCTION}

Silkworm variety resources are valuable wealth of all human beings, an important component of biodiversity and one of China's most advantageous and distinctive genetic resources. A silkworm local variety is also known as a native variety, referring to a variety formed from long-term natural and artificial selections under local natural conditions. Due to longstanding geographic isolation, there is a difference in ecological character and economic character among various varieties. The Sericulture Institute of Chinese Academy of Agricultural Sciences preserves more than 700 silkworm varieties different in voltinism and moltinism collected from different regions, including local varieties from China and silkworm variety resources from other countries or regions such as Central Asia, Europe, Japan and India ${ }^{1}$. Furthermore, the general characters and special traits of these silkworm variety resources have been researched, providing precious basic materials for sericulture teaching, scientific research and silkworm breeding ${ }^{2,3}$.

The study of genetic differences, classification, evolution and genetic relationships of different silk- worm cultivars can benefit from the use of tools available from molecular biology for identification and preservation of silkworm germplasm resources. Hence such tools are potentially, of great significance for breeding silkworm cultivars.

Currently, silkworm varieties are still classified mainly based on morphological markers, which are, however, often susceptible to the environment and less stable. Instead, molecular markers, which are genetic markers evolved from the rich polymorphism of the genomic DNA, can directly reflect differences in DNA level among individual organisms $^{4-6}$. Hence it is an accurate, reliable and effective way to construct fingerprints of different silkworm varieties for variety classification and identification.

As 2nd-generation molecular markers were developed in recent years, Simple Sequence Repeats (SSR) markers have been widely used for molecular map construction, genetic diversity analysis, genetic relationship identification and molecular markers-assisted breeding due to its high stability, polymorphism and efficiency and compliance with the Mendelian genetic law ${ }^{7-13}$. Reddy et al ${ }^{14,15}$ initiated the research of silkworm varieties with 
SSR markers; Miao et al ${ }^{16}$ built an SSR markersbased genetic linkage map for silkworm varieties and mapped a series of silkworm genes based on different phenotype traits ${ }^{17-21}$; researchers built fingerprints for Chinese, Japanese and introduced silkworm varieties by using SSR markers ${ }^{22,23}$, laying a foundation for the identification and evaluation of silkworm variety resources. However, there remains a lack of related studies on domestic silkworm variety resources with local characteristics. Thus in this study, we built DNA fingerprints for the 96 silkworm local varieties with SSR markers, and clustered the genetic distance between various varieties with UPGMA to analyse the genetic relationship between the varieties, improving the silkworm variety resource bank.

\section{MATERIALS AND METHODS}

\section{Silkworm varieties}

The tested varieties consist of 83 Chinese univoltine varieties, 11 Chinese bivoltine varieties and 2 Japanese bivoltine varieties. Their main characters are shown in Table 1 . The above variety resources are preserved by the Sericulture Institute of Chinese Academy of Agricultural Sciences.

\section{Genomic DNA extraction}

Various varieties of silkworms were fed with mulberry leaves for 2 instars until incubation, and 10 silkworms were selected, mixed and put in a precooled mortar. Then the larvae were frozen quickly in liquid nitrogen and ground into powder. Subsequently, extraction buffer, containing $10 \mathrm{mM}$ Tris$\mathrm{HCl}, \mathrm{pH}$ 8.0, 0.1 M EDTA, and 0.5\% sodium dodecyl sulphate, was added to the powder. The mixture was transferred into Eppendorf tubes and incubated with Proteinase $\mathrm{K}$ at $56^{\circ} \mathrm{C}$ for $3-5 \mathrm{~h}$. The DNA was then purified by extraction with phenol/chloroform followed by ethanol precipitation. The purified DNA was dissolved in $0.1 \times$ TE buffer, refrigerated at $-20^{\circ} \mathrm{C}$ using the method from $\mathrm{Li}$ et $\mathrm{al}^{24}$.

\section{SSR markers and PCR amplification}

The SSR markers were acquired by the method based on Shen et al ${ }^{16}$, and Table 2 shows the characteristics of the 41 SSR markers. The PCR amplifier is Techne flexigene Cycler. The touchdown procedure was adopted for PCR amplification, and the procedure is as follows: pre-denaturation for $3 \mathrm{~min}$ at $94^{\circ} \mathrm{C}$, denaturation for $40 \mathrm{~s}$ at $94^{\circ} \mathrm{C}$, annealing for $40 \mathrm{~s}$ at $63^{\circ} \mathrm{C}$ and extension for $1 \mathrm{~min}$ at $72^{\circ} \mathrm{C}$. Then, PCR amplification was performed for 15 times, with the annealing temperature lowered to $0.44^{\circ} \mathrm{C}$ each time until to $56^{\circ} \mathrm{C}$; the following is the condition for the last 24 times of amplification: denaturation for $40 \mathrm{~s}$ at $94^{\circ} \mathrm{C}$, annealing for $40 \mathrm{~s}$ at $56^{\circ} \mathrm{C}$, extension for $1 \mathrm{~min}$ at $72^{\circ} \mathrm{C}$. PCR reaction system $15 \mu$, containing $1 \times$ PCR buffer ( $10 \mathrm{mM}$ Tris- $\mathrm{HCl}, 1.5 \mathrm{mM}$ $\mathrm{MgCl}_{2}, 50 \mathrm{mM} \mathrm{KCl}, \mathrm{pH}$ 8.3), $200 \mu \mathrm{M}$ dNTPs, 10 $\mathrm{pM}$ of $5^{\prime}$ apex primer and $3^{\prime}$ apex primer, $0.5 \mathrm{U}$ Taq polymerase and $20 \mathrm{ng}$ of template DNA.

\section{PIC value calculation}

According to the results of amplification of various SSR markers among the 96 silkworm varieties, the polymorphic index content (PIC) ${ }^{21}$ of various SSR markers was calculated by the formula below:

$$
\mathrm{PIC}=1-\sum_{i} p_{i}^{2}
$$

where $p_{i}$ represents the frequency of occurrence of $i$ allele in the 96 local varieties.

\section{Electrophoresis}

PCR products were tested with ABI 377 automatic sequencer. The concentration of denaturing gel was $5 \%$ and the length was $36 \mathrm{~cm}$. After PCR products were diluted to $0.4 \mathrm{ng} \mathrm{DNA} / \mu \mathrm{l}, 1 \mu \mathrm{l}$ plus $3 \mu \mathrm{l}$ of buffer (containing $5 \mathrm{mg} / \mathrm{ml}$ of dextran blue and $5 \%$ deionized formamide) was added, and placed on ice for use after 3-min denaturation at $95^{\circ} \mathrm{C}$. For sample injection, $0.2 \mu \mathrm{l}$ of fluorescent markers (ABI, rox 400 , containing $80,100,150,180,200,250$, $300,320,350,400$ bp fluorescently-labelled DNA fragments) first, and then $0.5 \mu \mathrm{l}$ of denatured sample was added. Electrophoresis was performed for $2 \mathrm{~h}$ under the following condition: electrophoresis buffer $1 \times \mathrm{TBE}$, voltage $3000 \mathrm{~V}$, current $50 \mathrm{~mA}$ and gel temperature $51^{\circ} \mathrm{C}$.

\section{Data analysis}

With the rox400 internal standard as reference, an amplified band of certain size appeared in a particular position after primer electrophoresis, and Gene Scan Analysis Software v.3.1 was used to calculate the size of each amplified fragment. Each observed polymorphic band was regarded as a trait, with a value of ' 1 ' and a value of ' 0 ' when no polymorphic band was observed. The genetic distance was expressed in absolute distance and calculated with Microsat v.1.5 (E.M inch, Stanford University, USA). Subprograms NEIGHBOR and DRAWGRAM in PHYLIP software package (v.3.57 c. Joe Felsenstein, University of Washington, USA) were used as 
Table 1 Characteristics of silkworm strains used in the present study.

\begin{tabular}{|c|c|c|c|c|c|c|c|c|c|}
\hline No. & Strain name & System & Voltinism & Moltinism | & No. & Strain name & System & Voltinism & Moltinism \\
\hline pop1 & Huiseluan & Chinese & V1 & M4 & pop49 & Tongshan No. 24 & Chinese & V1 & M4 \\
\hline pop2 & $3011(D)$ & Chinese & V1 & M4 & pop50 & Xinyi No. 19 & Chinese & V1 & M4 \\
\hline pop3 & Sanmianbai & Chinese & V1 & M3 & pop51 & Sihong No. 15 & Chinese & V1 & M4 \\
\hline pop4 & Sanmianbailuan & Chinese & V1 & M3 & pop52 & Peixian No. 1 & Chinese & V1 & M4 \\
\hline pop5 & Duodueibanyueban & Chinese & V2 & M4 & pop53 & Fengxian No. 8 & Chinese & V1 & M4 \\
\hline pop6 & Xinlongjiao & Chinese & V2 & M4 & pop54 & Yancheng No. 2 & Chinese & V1 & M4 \\
\hline pop7 & 207 & Chinese & V2 & M4 & pop55 & Mianyanghong & Chinese & V1 & M4 \\
\hline pop8 & C2 zhe & Chinese & V2 & M4 & pop56 & Xupuzhong & Chinese & V1 & M4 \\
\hline pop9 & C110 B & Chinese & V2 & M4 & pop57 & Changdejinhuang & Chinese & V1 & M4 \\
\hline pop10 & Yingwenpiban & Japanese & V2 & M4 & pop58 & Youxianzhong & Chinese & V1 & M4 \\
\hline pop11 & HehuiYinghan & Japanese & V2 & M4 & pop59 & Handanzhong & Chinese & V1 & M4 \\
\hline pop12 & 3011(Oxin3) & Chinese & V2 & M4 & pop60 & Datuanyuan & Chinese & V1 & M4 \\
\hline pop13 & 3011(B4xin2) & Chinese & $\mathrm{V} 2$ & M4 & pop61 & Jinhuang & Chinese & V1 & M4 \\
\hline pop14 & $3011(5 x i n 1)$ & Chinese & $\mathrm{V} 2$ & M4 & pop62 & Jinguang & Chinese & V1 & M4 \\
\hline pop15 & Hehuihuaba & Chinese & $\mathrm{V} 2$ & M4 & pop63 & Bilian & Chinese & V1 & M4 \\
\hline pop16 & Songhuaxingwu & Chinese & V2 & M4 & pop64 & Zhong No. 11 & Chinese & V1 & M4 \\
\hline pop17 & Heyuanlongjiao & Chinese & V2 & M4 & pop65 & Zhong No. 14 & Chinese & V1 & M4 \\
\hline pop18 & Fenshui No. 1 & Chinese & V1 & M3 & pop66 & Balinghuang & Chinese & V1 & M4 \\
\hline pop19 & Xiushui No. 2 & Chinese & V1 & M3 & pop67 & Jiaxingyoucan & Chinese & V1 & M4 \\
\hline pop20 & Suqian No. 1 & Chinese & V1 & M3 & pop68 & Yuhangbaipi & Chinese & V1 & M4 \\
\hline pop21 & Ermao & Chinese & V1 & M3 & pop69 & Jilisi & Chinese & V1 & M4 \\
\hline pop22 & Zhugui & Chinese & V1 & M3 & pop70 & Longwangtang & Chinese & V1 & M4 \\
\hline pop23 & Tangxisanmian & Chinese & V1 & M3 & pop71 & Zhuji & Chinese & V1 & M4 \\
\hline pop24 & Zunyi No. 1 & Chinese & V1 & M3 & pop72 & Xiaobaiyuan & Chinese & V1 & M4 \\
\hline pop25 & Zunyi No. 2 & Chinese & V1 & M3 & pop73 & Xunba & Chinese & V1 & M4 \\
\hline pop26 & Zhengan No. 1 & Chinese & V1 & M3 & pop74 & Taihuyucan & Chinese & V1 & M4 \\
\hline pop27 & Yanhe No. 1 & Chinese & V1 & M3 & pop75 & Songhuacanji & Chinese & V1 & M4 \\
\hline pop28 & SanmianA & Chinese & V1 & M3 & pop76 & Huayuan & Chinese & V1 & M4 \\
\hline pop29 & SanmianB & Chinese & V1 & M3 & pop77 & Wulong3030 & Chinese & V1 & M4 \\
\hline pop30 & Sanguang & Chinese & V1 & M3 & pop78 & 357 & Chinese & V1 & M4 \\
\hline pop31 & Lianyuen No. 1 & Chinese & V1 & M3 & pop79 & C17(zhuwu) & Chinese & V1 & M4 \\
\hline pop32 & Shangqiu No. 1 & Chinese & V1 & M3 & pop80 & 9008 & Chinese & V1 & M4 \\
\hline pop33 & Mengzi No. 1 & Chinese & V1 & M3 & pop81 & $3042(18)$ & Chinese & V1 & M4 \\
\hline pop34 & Luhuang1 & Chinese & V1 & M3 & pop82 & Gong No. 2 & Chinese & V1 & M4 \\
\hline pop35 & $43 x i n$ & Chinese & V1 & M4 & pop83 & Chuan35(1-4) & Chinese & V1 & M4 \\
\hline pop36 & 47xin & Chinese & V1 & M4 & pop84 & Linchengzhong & Chinese & V1 & M4 \\
\hline pop37 & 47qiao & Chinese & V1 & M4 & pop85 & Zhecan (hang) & Chinese & V1 & M4 \\
\hline pop38 & Chaoxianzhong & Chinese & V1 & M4 & pop86 & Zhenze & Chinese & V1 & M4 \\
\hline pop39 & Xiaofeng No17 & Chinese & V1 & M4 & pop87 & Lu108 & Chinese & V1 & M4 \\
\hline pop40 & Anji No. 7 & Chinese & V1 & M4 & pop88 & Zhong20xi & Chinese & V1 & M4 \\
\hline pop41 & Yuhang11 & Chinese & V1 & M4 & pop89 & Zhong21yu & Chinese & V1 & M4 \\
\hline pop42 & Yuhang24 & Chinese & V1 & M4 & pop90 & Yanjizhong & Chinese & V1 & M4 \\
\hline pop43 & Yiwu No. 10 & Chinese & V1 & M4 & pop91 & Hangui(wu) & Chinese & V1 & M4 \\
\hline pop44 & Xinchang No. 12 & Chinese & V1 & M4 & pop92 & $\begin{array}{l}\text { CAzhe } \\
\text { lo }\end{array}$ & Chinese & V1 & M4 \\
\hline pop45 & Linhai No. 39 & Chinese & V1 & M4 & pop93 & Xugui(wu) & Chinese & V1 & M4 \\
\hline pop46 & Ninghai No. 20 & Chinese & V1 & M4 & pop94 & Xingshan No. 1 & Chinese & V1 & M3 \\
\hline pop47 & Fenghua No. 7 & Chinese & V1 & M4 & pop95 & Xingshan No. 2 & Chinese & V1 & M4 \\
\hline pop48 & Pixian No. 3 & Chinese & V1 & M4 & pop96 & Lanxi2 & Chinese & V1 & M4 \\
\hline
\end{tabular}

Voltinism: the number of generations that occur in one year. Bombyx mori can be divided into three types: univoltine (V1), bivoltine (V2) and polyvoltinism (V3). Moltinism: A characteristic number of times that silkworms molt three (M3) or four-times (M4).

analysis software, and UPGMA was used to cluster the genetic distance between all the varieties, obtaining a tree diagram.

\section{RESULTS}

The number of alleles in silkworm varieties and the PIC of SSR markers

525 different DNA fragments (data unlisted) were amplified from the 41 SSR markers in the 96 varieties, with 1 SSR marker corresponding to 12.80 alleles averagely ( $\min 3$, max 35$)$. The mean PIC value of the 41 SSR loci was 0.69 (min 0.162 , max 0.958) (Table 2).

\section{Fingerprint construction}

After amplification with 41 SSR primers, a series of specific amplifications emerged at the corresponding loci for each local variety. The size of each amplified band could be read off after electrophoresis with ABI 377 sequencer (Fig. 1). The polymorphic bands amplified by each SSR primer were sorted, and typical SSR marker-based fingerprint of each variety was determined. As shown in Fig. 1, it is the SSR electrophoresis map of 23 varieties of pop1pop23 with primer FL0547, and the number and the size of bands can be read out. As can be seen from Fig. 1, no polymorphic bands of pop9, pop13, 
Table 2 Microsatellite loci, repeat motif, forward and reverse flanking primer sequences, number of alleles, allelic size range, and PIC values in Bombyx mori.

\begin{tabular}{|c|c|c|c|c|c|}
\hline Locus & Repeat & Primer sequence $\left(3^{\prime}-5^{\prime}\right)$ & No. & Size range & PIC \\
\hline FL0308 & CT & gcgacgcactccatcaagc tgctttcgtcctttcttatccet & 8 & $104-148$ & 0.776 \\
\hline FL0315 & CA & tcgccgagttggctggt cgtgtaaacatgtatcccgagttg & 5 & $150-160$ & 0.715 \\
\hline FL0317 & CT & cccaccaggtaaggttggtaca ggaaatggtagtgcaaggtagagg & 17 & $148-182$ & 0.735 \\
\hline FL0542 & CT & tgaaatcagttgaggcggaaaa cttgctaatcgaattcatgattgtaa & 18 & $234-282$ & 0.895 \\
\hline FL0547 & CT & cacaggatgacttggtaaaacgg gctttcagtaaaattattttgaatttga & 6 & $288-308$ & 0.257 \\
\hline FL0612 & CA & cagatttcgccaggactacacttt gagaagtgcagagtgcccatatt & 14 & $220-264$ & 0.841 \\
\hline FL0617 & CT & aagttcttgagtggcgaccg caagaaccgcagacactccaa & 14 & $232-312$ & 0.817 \\
\hline FL0910 & CT & acagacttaacttaaaacggattgaaa cgttgtagatgtctatgggctcc & 4 & $234-246$ & 0.478 \\
\hline FL0915 & CT & tgctgaaggacaaaagggaatg cattgtggatgtctacgggctc & 25 & $172-300$ & 0.893 \\
\hline FL0932 & CT & cagtccttgtcagttgccattgt aaccgttaaatgagacgtgcg & 8 & 224-300 & 0.566 \\
\hline FL0939 & CT & ggtgtattcgtaacaagtagggcg tcttctttgtctcctacttatcccact & 6 & $290-310$ & 0.423 \\
\hline FL1003 & CT & aaagttttctggagcgaagcg ccctgcagttgctcgtatgtc & 35 & $94-196$ & 0.958 \\
\hline FL1019 & CA & cacctagttttacttcacggaccat cccttgggcttaagtcggttt & 15 & $220-258$ & 0.778 \\
\hline FL1027 & CT & actcaccaacaaaccgcaaga caccgcaacatgcctgctata & 22 & $132-282$ & 0.834 \\
\hline FL1028 & CT & agctgtggtcggcatatgaagt gccagttttgaagggtcgg & 31 & $250-330$ & 0.808 \\
\hline FL1148 & CA & gcctttatctttgaacgatcattga ccccttattacgaaaAttgcgc & 19 & $322-400$ & 0.888 \\
\hline FL1160 & CA & ggagtcccgcatcccgataa atcatgtcagacctaagcactcaaa & 14 & $304-346$ & 0.820 \\
\hline FL1162 & CA & tttgttgttcataaggtccgca gattccgacgatagatttgacga & 8 & $349-367$ & 0.762 \\
\hline FL1163 & CA & cagtggtttatttgtacggcagaa atggagtgcttctagatgcctagtt & 4 & 334-342 & 0.621 \\
\hline
\end{tabular}

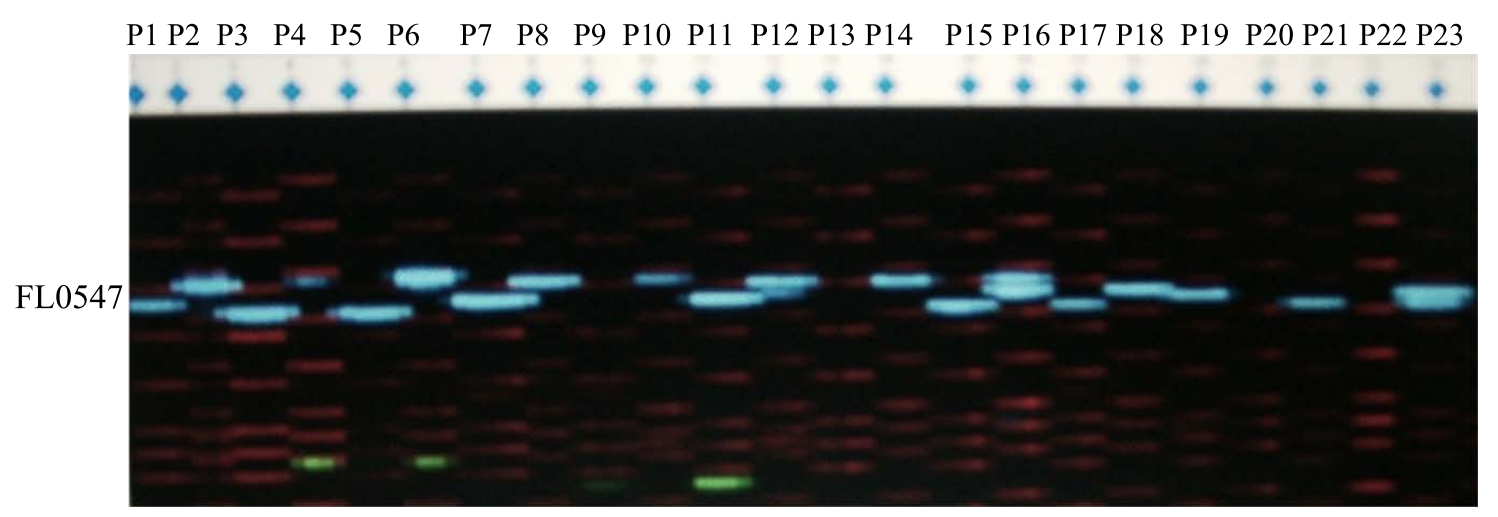

Fig. 1 Amplification results of FL0547 in silkworm variety pop1-pop23. 
pop20 and pop23 appeared after the amplification of FL0547, but one or more bands of different lengths were amplified for the other 19 varieties, respectively. By analogy, the SSR polymorphism bands of all local varieties amplified by each SSR primer were sorted out, and the SSR amplification bands of each local variety were obtained, that is, the SSR marker fingerprint of each variety.

\section{Genetic distance analysis and cluster analysis}

The genetic distance between the varieties was calculated according to the results of amplification with SSR markers. The genetic distance between Jinhuang (pop61) and Jinguang (pop62) was the smallest (0.1101), and hence, the first to cluster; followed by SanmianA (pop28) and SanmianB (pop29) group, (genetic distance $=0.1152$ ), and then by Minayanghong (pop55) and Youxianzhong (pop58) with a genetic distance estimate of 0.1203. The furthest distances was observed between Xingshan No. 1 (pop94) and other varieties, reaching values of up to 0.2381 , indicating that Xingshan No. 1 was least closely related to other varieties. The mean genetic distance among the varieties was 0.1621 .

According to the genetic distance among the varieties, UPGMA was used to draw a cluster map for the 96 silkworm varieties, as shown in Fig. 2 There were relatively complex clusters among the silkworm varieties, that could be broadly assigned into the following groups: the first group consisted of 6 univoltine trimolters, 6 bivoltine tetramolters and 8 univoltine tetramolters, involving 20 varieties; the second group consisted of 7 univoltine trimolters and 7 univoltine tetramolters, involving 14 varieties; the third group consisted of 9 varieties, including 3 bivoltine tetramolters, 2 univoltine trimolters and 4 univoltine tetramolters; the fourth group consisted of 8 varieties, including 1 univoltine trimolter and 7 univoltine tetramolters; the fifth group, a relatively centralized group, consisted of 6 univoltine tetramolters and 1 univoltine trimolter. It could be seen from the above results that the varieties in each group included different geographical systems (Chinese or Japanese), different voltinism and moltinism types of behaviour, and that these five groups were clustered with other subgroups based on distances. The remaining 42 varieties were not clustered in any obvious manner. Mostly, 2 or 3 varieties could be clustered together, while some others, such as Huiseluan (pop1), Jilisi (pop69), Peixian No. 1 (pop52), Xiushui No. 2 (pop19), Wulong 3030 (pop77) and Xingshan No. 2 (pop95), were on lone branches. Xingshan No. 1 (pop94) was clustered separately alone from the remaining 95 varieties.

\section{DISCUSSION}

The core structure of McRoatellite DNA is a sequence of dozens of nucleotides composed of 1-6 nucleotides in series, with the variation of the number of repeating units forming the polymorphism of SSR markers. It is generally recognized that the number of repeating units is positively correlated with the number of alleles at the locus. But in silkworm genomes, Reddy et $\mathrm{al}^{15}$ and Hou et al ${ }^{22}$, discovered that the length of repeated SSR fragments has nothing to do with polymorphism. In this study, the FL0910 and FL1163 amplified fragments of 4 alleles were 234-246 bp and 334-342 bp, respectively. Although the same number of fragments was amplified from the 2 primers, there was a big difference in the size of the amplified fragments; the FL1003 amplified fragment of 35 alleles was just 94$196 \mathrm{bp}$. This shows that the results of this study support the previous viewpoints, and the length of the SSR amplified fragments in silkworm genomes has nothing to do with SSR polymorphism.

SSR is widespread throughout various eukaryotic genomes, and there are many reports ${ }^{25-27}$ on the use of SSR to research species revolution and classification. As can be seen from dozens of species of animals and plants concerned, the SSR technique can quicken material classification and identification accurately. Our team applied SSR to SSR fingerprint construction for different geographic silkworm varieties and to genetic relationship studies ${ }^{17,22,23}$ concluding that SSR could accurately classify silkworm varieties systematically and even analyse the difference in one variety caused by egg colour ${ }^{23}$. Thus it can be seen that the SSR marker technique is an effective method for researching the genetic differences between silkworm varieties. As shown by the results of this study, the varieties from the same place, such as Xingshan No1 and Xingshan No. 2, Yuhang No. 11 and Yuhang No. 24, are separated far from each other in terms of genetic distance, suggesting that gene swapping didn't occur when they were collected, and their primary characteristics were retained. Thankfully, these varieties have been strictly protected against admixture in the past decades due to preservation, with their local characteristics retained, ensuring the diversity of silkworm variety resources.

It is recognized that domestic silkworms are tamed wild silkworms, but there are differences in varietal evolution and classification among the 


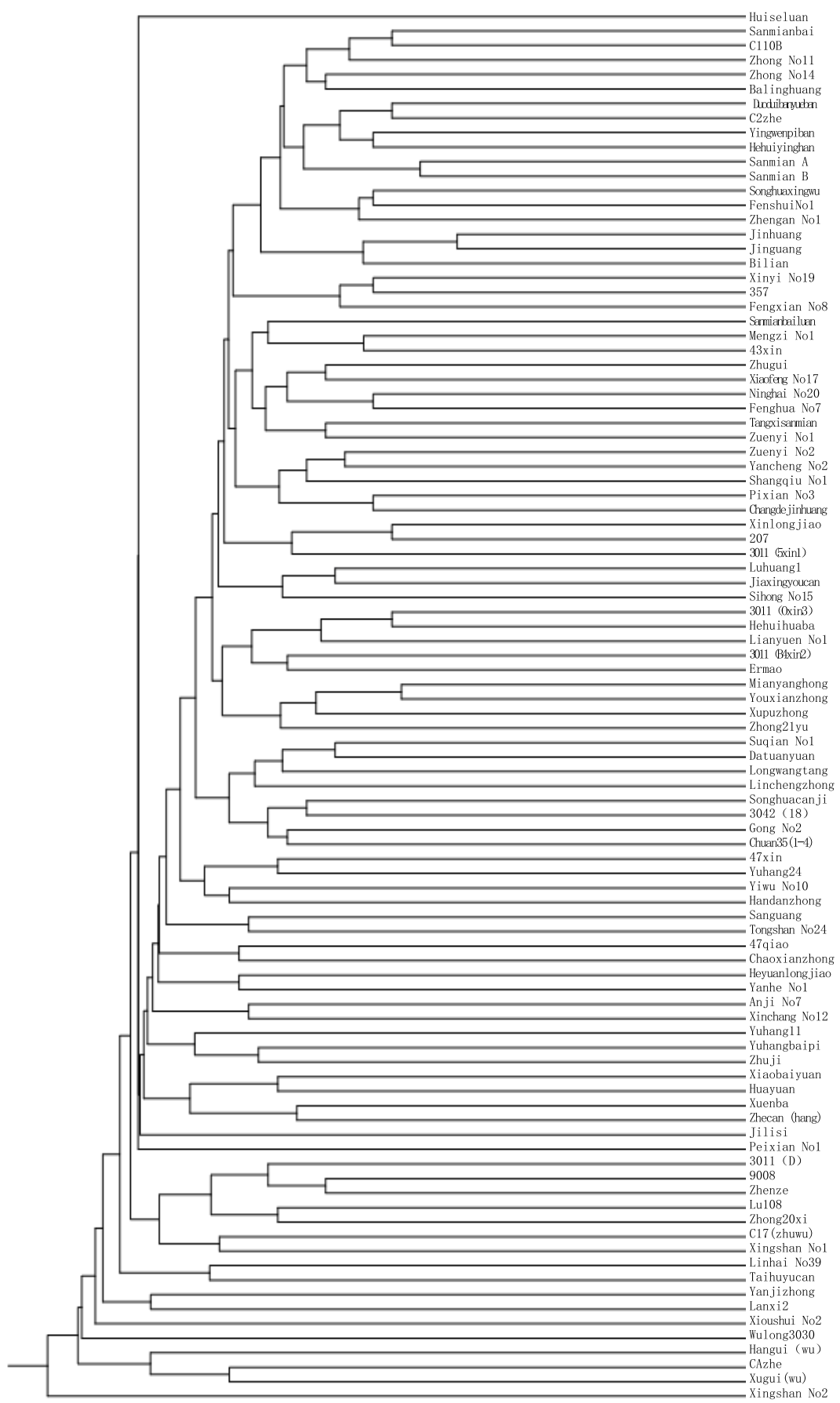

Fig. 2 Phylogenetic tree of silkworm races.

domestic silkworms. Some scholars also argue that multivoltine silkworms differentiated early and have many centres of origin. However, Xiang et $\mathrm{al}^{1}$ suggested Chinese univoltine variety represents the original centre of silkworm. In recent years, molecular-genetic techniques have opened up a new way for research into the origin and evolution of species. This has, enabled people to analyse genetic differences between species and varieties through genome-based information, giving a big push to research on the origin and evolution of silkworms. Based on results using the RAPD technology, Xia et $\mathrm{al}^{28}$ showed that the Chinese univoltine tetramolter was the earliest tamed wild silkworm, 
Huiseluan(mutant)

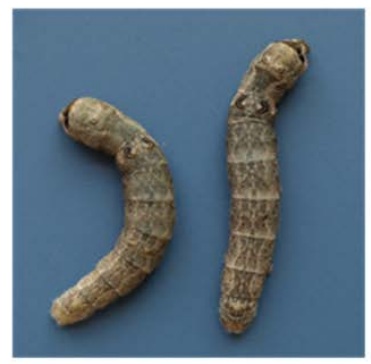

Wulong3030(mutant)

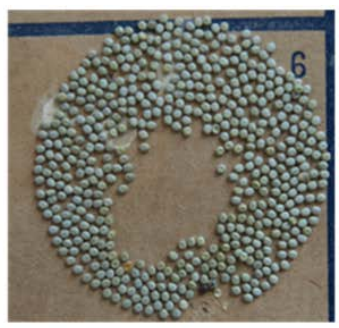

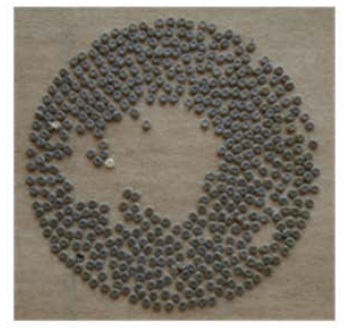

Contrast(wild)

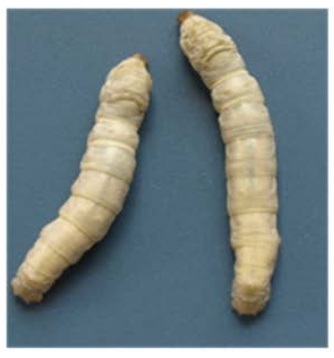

Contrast(wild)
Fig. 3 Some mutant varieties used in this study.

and that the Chinese univoltine trimolter and univoltine tetramolter belonged to two groups with a significant difference in evolution. Lu et $\mathrm{al}^{29}$ researched silkworm evolution using AFLP, the results confirming that domestic silkworms were evolved from Chinese wild silkworms, and pointed that there were already univoltine, bivoltine and multivoltine silkworms in the early days of domestication, and those silkworms grew into different varieties; Hou et $\mathrm{al}^{22}$ analysed the evolution of the European univoltine, Japanese univoltine and Chinese bivoltine silkworms with the SSR technique, verifying the theory of mixed origin put forward by $\mathrm{Lu}$ et $\mathrm{al}^{29}$. Of the 96 objects of this study, there are 63 Chinese univoltine tetramolter varieties, 20 Chinese univoltine trimolter varieties, 11 Chinese bivoltine tetramolter varieties and 2 Japanese bivoltine tetramolter varieties. But in the molecular cluster map, the varieties of the same voltinism or moltinism were not clustered together, whereas the varieties of different voltinism and moltinism are clustered in an interpenetrating way. The research results seem to support the conclusion that silkworms have multiple original centres.

In addition, if a mutation occurs in a trait of a variety, it may also lead to the special alienation of the variety on the molecular evolutionary tree. For example, Huiseluan (pop1) in this study collected from wuxian county, jiangsu province, and its egg colour was mutated with grey and deep egg stripes.
Wulong 3030 (pop77) is a local species collected in yuyao county, Zhejiang province, while the larva's markings and body colour were mutated to show dark brown markings (Fig. 3). These research results seem to support the conclusion that mutations of these traits may be related to SSR loci involved in this study, so these varieties do not cluster into groups with other varieties.

\section{CONCLUSIONS}

SSR markers have rich polymorphism in silkworm variety resources. With high repeatability, usability (PCR markers) and testability (by polyacrylamide gel electrophoresis), SSR markers can be used to build fingerprints of silkworm variety resources, analyse the genetic relationship between silkworm variety resources and set up a core variety bank of silkworms.

All the 96 silkworm varieties in this study are fully distinguished from one another with SSR markers, suggesting that SSR markers are suitable for variety identification, especially providing evidence about DNA levels for the identification of the varieties involved in intellectual property disputes.

The results of this study basically accord with the theory of mixed origin put forward by Takeyoshi Yoshinari and Lu Cheng that different silkworm local varieties are not clustered together by the same voltinism or moltinism, but more evidence is needed.

Acknowledgements: This work was supported by the Natural Science Foundation of Jiangsu Province (Grant No. BK20181228), The Natural Science Foundation of the Jiangsu Higher Education Institutions of China (No. 17KJB230001), Key Research \& Development program of Zhenjiang (NY2017017, NY2018021).

\section{REFERENCES}

1. Xiang H, Liu XJ, Li MW, Zhu YN, Wang LZ, Cui Y, Liu LY, Fang GQ, et al (2018) The evolutionary road from wild moth to domestic silkworm. Nat Ecol Evol 2, 1268-1279.

2. Yi WZ, Qin J (1991) Progress of silkworm germplasm resource research in China. Sci Agri Sinica 4, 47-51.

3. Lin CQ, Chen KP, Wu DX, Yao Q (2003) Investigations on specific characteristics of germplasms in Bombyx mori. Sci Agri Sinica 6, 709-713.

4. Garrido-Cardenas JA, Mesa-Valle C, ManzanoAgugliaro F (2018) Trends in plant research using molecular markers. Planta 247, 543-557.

5. Tillmar AO, Phillips C (2017) Valuation of the impact of genetic linkage in forensic identity and relationship testing for expanded DNA marker sets. Forensic Sci Int Genet 26, 58-65. 
6. Mohr AM, Mott JL (2015) Overview of microRNA biology. Semin Liver Dis 35, 3-11.

7. Shubhneet K, Panesar PS, Bera MB, Varinder K (2014) Simple sequence repeat markers in genetic divergence and marker-assisted selection of rice cultivars: a review. Crit Rev Food Sci Nutr 55, 41-49.

8. Bhat JA, Ali S, Salgotra RK, Mir ZA, Dutta S, Jadon V (2016) Genomic selection in the era of next generation sequencing for complex traits in plant breeding. Front Genet 7, ID 221, 1-11.

9. Vieira MLC, Santini L, Diniz AL, Munhoz CDF (2016) Microsatellite markers: what they mean and why they are so useful. Genet Mol Biol 39, 312-328.

10. Liu L, Qin M, Yang L, Song Z, Luo L, Bao H, Ma ZG, Zhou ZY, et al (2017) A genome-wide analysis of simple sequence repeats in Apis cerana and its development as polymorphism markers. Gene 599, 53-59.

11. Li G, Ra WH, Park JW, Kwon SW, Lee JH, Park CB, Park YJ (2011) Developing EST-SSR markers to study molecular diversity in Liriope and Ophiopogon. Biochem Syst Ecol 39, 241-252.

12. Ali S, Müller CR, Epplen JT (1986) DNA finger printing by oligonucleotide probes specific for simple repeats. Hum Genet 74, 239-243.

13. Renuka G, Shamitha G (2016) Genetic variation in ecoraces of tropical tasar silkworm, Antheraea mylitta using SSR markers. $J$ Genet 95, 777-785.

14. Reddy KD, Abraham EG, Nagaraju J (1999) Microsatellites in the silkworm, Bombyx mori: abundance, polymorphism, and strain characterization. Genome 42, 1057-1065.

15. Reddy KD, Nagaraju J, Abraham EG (2010) Genetic characterization of the silkworm Bombyx mori by simple sequence repeat (SSR)-anchored PCR. Heredity 83, 681-687.

16. Miao XX, Xub SJ, Li MH, Li MW, Huang JH, Dai FY, Marino SW, Mills DR, et al (2005) Simple sequence repeat-based consensus linkage map of Bombyx mori. Proc Natl Acad Sci USA 102, 16303-16308.

17. Li M, Guo Q, Hou C, Miao X, Xu A, Guo X, Huang YP (2006) Linkage and mapping analyses of the densonucleosis non-susceptible gene nsd-Z in the silkworm Bombyx mori using SSR markers. Genome 49, 397-402.

18. Zhao YP, Li AY, Hou CX, Li MH, Guo QH, Huang YP (2008) SSR based linkage and mapping analysis of C, a yellow cocoon gene in the silkworm, Bombyx mori.
Insect Sci 15, 399-404.

19. Li Xia, Li MW, Guo QH, Xu AY, Huang YP (2008) Mapping of the yellow inhibitor gene I in silkworm Bombyx mori using SSR markers. Hereditas 30, 1039-1042.

20. Wei GQ, Yu L, Liu CL, Zhu BJ, Ding HJ (2013) Linkage and mapping analyses of the normal marking gene $+P$ in the silkworm (Bombyx mori) using SSR markers. Genet Mol Res 12, 2351-2359.

21. Nuan N, Niu BL, Wang HL, Li Z Meng ZQ (2010) Mapping of the lethal genes in the sex-linkaged balanced lethal silkworm Bombyx mori using SSR markers. Hereditas 32, 1269-1274.

22. Hou CX, Li MW, Zhang YH, Qian HY, Sun PJ, Xu AY (2007) Analysis of SSR fingerprints in introduced silkworm germplasm resources. Agri Sci China 6, 620-627.

23. Qian HY, Li MW, Zhang YH, Guo QH, Xiang X, Zhao YP, Sun PJ, Hou CX, et al (2005) Construction of fingerprints of silkworm germplasm resources and analysis of phylogenic relationships based on SSR markers. Acta Sericologica Sinica 31, 422-428.

24. Li MW, Hou CX, Miao XX, Xu AY, Huang YP (2007) Analyzing genetic relationships in Bombyx mori using intersimple sequence repeat amplication. $J$ Econ Entomol 100, 202-208.

25. Deng P, Wang M, Feng K, Cui L, Tong W, Song W, Nie XJ (2016) Genome-wide characterization of microsatellites in Triticeae species: abundance, distribution and evolution. Sci Rep 6, ID 32224, 1-13.

26. Wang F, Yang T, Burlyaeva M, Li L, Jiang J, Li F, Redden R, Zong X (2015) Genetic diversity of Grasspea and its relative species revealed by SSR markers. Plos One 10, ID e0118542, 1-14.

27. Moncrief I, Garzon C, Marek S, Stack J, Gamliel A, Garrido P, Proarfl F, Gard M,et al (2016) Development of simple sequence repeat (SSR) markers for discrimination among isolates of Fusarium proliferatum. $J$ Microbiol Methods 126, 12-17.

28. Xia Q, Zhou ZY, Lu C, Xiang ZH (1998) Molecular phylogenetic study on the racial differentiation of Bombyx mori by random amplified polymorphic DNA (RAPD) markers. Acta Entomologica Sinica 1, 32-40.

29. Cheng LU, Hong-Shi YU, Xiang ZH (2002) Molecular systematic studies on Chinese Mandarina silkworm (Bombyx mandarina M.) and domestic silkworm (Bombyx mori L.). Agri Sci China 1, 349-358. 